\title{
A NEW HYB RID APPROACH TO INTERN PROBLEMS: AHP AND DEMATEL
}

\author{
Erdem Aksakal* \\ Engineering Faculty \\ Gazi University \\ Ankara, TURKEY \\ E-mail: eaksakal@gazi.edu.tr \\ Metin Dağdeviren \\ Engineering Faculty \\ Gazi University \\ Ankara, TURKEY \\ E-mail: metindag@gazi.edu.tr \\ Ihsan Yüksel \\ Faculty of Economic and \\ Administrative Sciences \\ Kırikkale University \\ Kirikkale, TURKEY \\ E-mail: yuksel@kku.edu.tr
}

\begin{abstract}
In nowadays because of huge rises in different kind of diseases health care systems become much more important and complex. Having complexity causes big responsibility and this forces the health care systems to improve itselves. The improvement can be considered in two sides: service and the patient. Both sides have the responsibilities on each other. In service side interns, which is someone who works in a temporary position with an emphasis on on-the-job training rather than merely employment making it similar to an apprenticeship, have the big part of the responsibility for the quality of the service because they will be the future of the health care system and they will give the shape of the system in a while. This paper presents a new look through the eyes of intern doctors for the health care system in order to understand the feelings and needs of them about the system. In the paper AHP and DEMATEL method was used as a hybrid model.
\end{abstract}

Keywords: Health care; Analytic hierarchy process; DEMATEL Method; Decision making.

\section{Introduction}

This paper focuses on the application of the AHP with DEMATEL method together to identify the most biggest problem that the interns faced with in health care system. In order to identify the problem, an old study which has a lot of problems dealing with health care system used which was prepared by Yuksel and Kurt (1998). The problems taken as criterias were selected by an expert panel to identify the problem much more clear. Expert panel which is formed by doctors which were interns until shortly. After making the decision of the problems, proposed model structured with the most faced 6 problems as a hierarchy. The structured model criterias then compared with each other with respect standardized comparison scale and then applying the DEMATEL method to the comparison matrix, the conclusion of the proposed method will be obtained.

* Corresponding Author 
The AHP developed by Saaty (1980) is a known multiattribute weighting method for decision support. Several authors have discussed the use of the AHP across a broad range of applications in health and medical decision making. Hatcher (1994) describes how the AHP can be included within a group decision support process (GDSS) and how the resulting system can be applied in a variety of health care decision making settings. Sloane, Liberatore and Nydick (2002) discusses the applicability of the AHP for medical and hospital decision support and briefly describes three completed studies and three on-going studies( Liberatore and Nydick (2008).

This paper is divided into five sections. Section 2 presents the methods that will be used for solving the model. Section 3 is prepared to identify the proposed model through AHP and DEMATEL. Section 4 discusses the numerical example applied to the proposed model and finally Section 5 concludes the paper.

\section{Methods}

\subsection{AHP Method}

AHP, developed by Saaty (1980), addresses how to determine the relative importance of a set of activities in a multi-criteria decision problem. The AHP method is based on three principles: first, structure of the model; second, comparative judgment of the alternatives and the criteria; third, synthesis of the priorities.

In this study we will use the first and the criteria part of the second step of this method for this AHP uses multiple pairwise comparisons are based on a standardized comparison scale of nine levels (Table1).

\subsection{DEMATEL Method}

The DEMATEL method, developed by the Science and Human Affairs Program of the Battelle Memorial Institute of Geneva between 1972 and 1976, can convert the relationship between the caus es and effects of criteria into an intelligible structural model of the system (Hung, Chou and Tzeng (2006); Tzeng, Chiang and Lee (2007).

The DEMATEL, used to research and solve complicated and intertwined problems, has been successfully applied in many situations, such as marketing strategies, R\&D project, e-learning evaluation, managers' competencies, control systems and airline safety problems (Chiu, Chen, Tzeng and Shyu 2006; Hori and Shimizu 1999; Lin and Wu 2008; Liou, Tzeng, Chang 2007; Tzeng, Chang, Li 2007; Wu and Lee 2007).

\section{The Proposed Model}

The proposed model was applied for an univers ity hospital in Türkiye, interns problems are discussed as health care system problem. Objective of the selection is to find the most biggest problem for the interns which is a very important process in health system. The proposed model was applied to this problem and the computational procedure is summarized as follows.

An expert team work for to define the criteria to be considered for to determine the most important problem of the health care system for interns. 6 criterias were agreed and to be included in the determination of the problem for applying within the interns: $\left(C_{1}\right)$ lack of coordinates, $\left(C_{2}\right)$ obligation to work after the attendance, $\left(\mathrm{C}_{3}\right)$ large number of attendance, $\left(\mathrm{C}_{4}\right)$ large number of workload in attendance $\left(\mathrm{C}_{5}\right)$ obligation to work in weekends, $\left(\mathrm{C}_{6}\right)$ due to the lack of enough staff, having lack of interns. Criteria 
to be considered in determination of problem process, criteria weights, dependence among criteria would be under the responsibility of this team.

\section{A Numerical Application of Proposed Model}

\subsection{Calculate the weights of criteria}

Criteria weights were determined by avoiding the interdependence among criteria. A pairwise comparison matrix was formed and pairwise comparisons were defined by the expert team in a group study. The consistency ratio value for this pairw ise comparison matrix is 0.0886 , which is acceptable $(\leq 0.1)$. At the end of pairwise comparisons, criteria weights were calculated (w vector)

$$
w=\left[\begin{array}{cccccc}
1 & 2 & 3 & 3 & 4 & 3 \\
0,5 & 1 & 0,33 & 2 & 0,2 & 0,5 \\
0,33 & 3 & 1 & 3 & 0,5 & 2 \\
0,33 & 0,5 & 0,33 & 1 & 0,33 & 0,5 \\
0,25 & 5 & 2 & 3 & 1 & 2 \\
0,33 & 2 & 0,5 & 2 & 0,5 & 1
\end{array}\right]=\left[\begin{array}{c}
0,348 \\
0,089 \\
0,166 \\
0,064 \\
0,222 \\
0,112
\end{array}\right]
$$

According to the calculation made, $\mathrm{C}_{1}, \mathrm{C}_{5}$ and $\mathrm{C}_{3}$ were three of the most important considering criteria relating to the evaluation.

\subsection{Determining Interde pendence Among Criterias}

In order to determine the interdependence between the criteria, we use the DEMATEL method. The DEMATEL method can convert the relationship between the causes and effects of criteria into an intelligible structural model of the system. Using the comparison scale of the DEMATEL method (Table 1) we produced the initial direct-relation matrix with us ing as follows in Table 2.

Table 2: The initial direct-relation matrix.

\begin{tabular}{|c|c|c|c|c|c|c|}
\hline & $\mathrm{C}_{1}$ & $\mathrm{C}_{2}$ & $\mathrm{C}_{3}$ & $\mathrm{C}_{4}$ & $\mathrm{C}_{5}$ & $\mathrm{C}_{6}$ \\
\hline $\mathrm{C}_{1}$ & 0 & 2 & 1,67 & 1 & 2,67 & 3,67 \\
\hline $\mathrm{C}_{2}$ & 1,33 & 0 & 2 & 1,67 & 2 & 1,67 \\
\hline $\mathrm{C}_{3}$ & 3 & 1,67 & 0 & 1 & 2 & 2,33 \\
\hline $\mathrm{C}_{4}$ & 2,67 & 1,3 & 1 & 0 & 2 & 1,67 \\
\hline $\mathrm{C}_{5}$ & 2 & 1,3 & 1,67 & 1,3 & 0 & 2 \\
\hline $\mathrm{C}_{6}$ & 2,67 & 1 & 2 & 1 & 2,33 & 0 \\
\hline
\end{tabular}

After finding the initial direct relation matrix the normalized direct-relation matrix $\mathrm{M}$ and total-relation matrix $\mathrm{S}$ can be obtained (Table3). 
Table 3: The total-relation matrix with $\mathrm{D}+\mathrm{R}$ and $\mathrm{D}-\mathrm{R}$ values.

\begin{tabular}{|c|c|c|c|c|c|c|c|c|}
\hline & $\mathrm{C}_{1}$ & $\mathrm{C}_{2}$ & $\mathrm{C}_{3}$ & $\mathrm{C}_{4}$ & $\mathrm{C}_{5}$ & $\mathrm{C}_{6}$ & $\mathrm{D}+\mathrm{R}$ & $\mathrm{D}-\mathrm{R}$ \\
\hline $\mathrm{C}_{1}$ & 0,752 & 0,641 & 0,6971 & 0,5006 & 0,9151 & 0,9979 & 9,2672 & $-0,2598$ \\
\hline $\mathrm{C}_{2}$ & 0,7053 & 0,3994 & 0,6022 & 0,4583 & 0,7249 & 0,7224 & 6,7691 & 0,4559 \\
\hline $\mathrm{C}_{3}$ & 0,9206 & 0,5957 & 0,54 & 0,4761 & 0,8327 & 0,885 & 7,8507 & 0,6495 \\
\hline $\mathrm{C}_{4}$ & 0,8065 & 0,511 & 0,5516 & 0,3427 & 0,7437 & 0,7463 & 6,3479 & 1,0557 \\
\hline $\mathrm{C}_{5}$ & 0,7363 & 0,4907 & 0,5698 & 0,4252 & 0,5694 & 0,7372 & 8,1125 & $-1,0553$ \\
\hline $\mathrm{C}_{6}$ & 0,8428 & 0,5188 & 0,6399 & 0,4432 & 0,7981 & 0,6596 & 8,6508 & $-0,846$ \\
\hline
\end{tabular}

Using the values of $\mathrm{D}-\mathrm{R}$ and $\mathrm{D}+\mathrm{R}$, a level of influence to others and a level of relationship with others are defined.

Receivers and Dispatchers can be seen clearly in Fig. 1. large number of attendance, inadequate wages, detention of personal rights are the dispatchers and obligation to work after the attendance, lack of drugs, consumables and medical devices, lack of coordinates, obligation to work in weekends are the receivers.

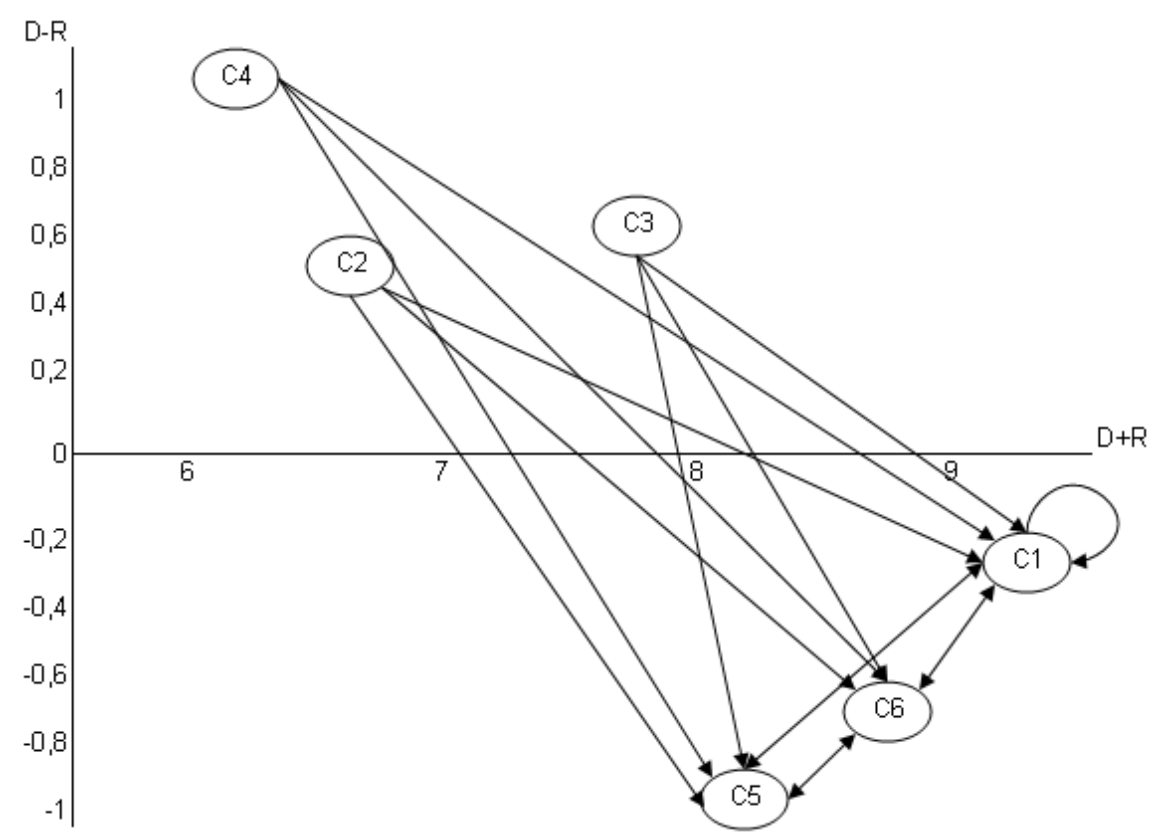

Fig.1. The impact-digraph-map of total relation - perspectives $(\mathrm{p} \geq 0.7)$.

To obtain an appropriate criteria dependence decision-maker must set a threshold value for the influence level. Only some elements, whose influence level in matrix are higher than the threshold value, can be chosen and converted into the criteria dependence figure. The threshold value is decided by the decisionmaker or by experts through discussion. Expert team decide the threshold value as 0.7 for this study and we found the dependence among criteria as presented in Fig 2.

Dependence among criteria is expressed as follows: $\mathrm{C}_{1}$ can be influenced by all criterias include itse lf. When the dependence among criteria is analyzed from a general perspective, it can be concluded that $\mathrm{C}_{2}$, 
$\mathrm{C}_{3}$ and $\mathrm{C}_{4}$ have dominant influences on the other criterias. Single direction arrow between $\mathrm{C}_{2}$ and $\mathrm{C}_{1}$ means that $\mathrm{C}_{2}$ criterion is influential on $\mathrm{C}_{1}$ criterion.

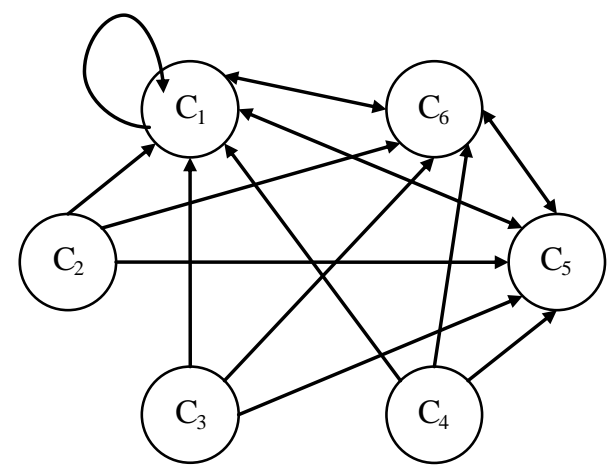

Fig 2. Dependence among criteria

After finding the dependence among criteria, normalized eigenvectors of dependence among criteria were calculated with pairwise comparison.

\subsection{Determine the relative importance of the crite rias}

Relative importance of the criteria on the basis of interdependence $\left(w_{c}\right)$ can be calculated as multiplying the degree of relative impact for criteria matrix with the criteria weights we found with AHP then we get the basis of interdependence as

$$
w_{c}=\left[\begin{array}{l}
C_{1} \\
C_{2} \\
C_{3} \\
C_{4} \\
C_{5} \\
C_{6}
\end{array}\right]=\left[\begin{array}{l}
0,1670 \\
0,1840 \\
0,2367 \\
0,1799 \\
0,0859 \\
0,1480
\end{array}\right]
$$

Most important three considering criteria relating to the the interdepence values become respectively $\mathrm{C}_{3}$, $\mathrm{C}_{3}$ and $\mathrm{C}_{4}$. Significant differences are observed in the results obtained for the criteria priorities (w vector) when interdependent priorities of the criteria $\left(\mathrm{w}_{\mathrm{c}}\right)$ and dependencies are not taken into account. For example the result change for the first criteria from 0,384 to 0,1670 . As shown from the results the dependence among criterias influenced the dependency so much.

\section{Conclusion}

In this study we try to find out the biggest health care problem in a different way, through the eyes of the interns. Interns are so important to the health care system and we get the answer as they are the future of the system because they will give the shape of the system in a while. This point of view motivate us to make this study.

In our study we deal with the intern doctors which has a big portion within the health care system. We studied together with the expert panel to identify the problems and afterwards for analyzing the results. The results show us attendance is the main problem. Large number of attendance and obligation to work after the attendance take the first two order and this may caused by lack of enough interns in the system. 
The other important part of our proposed model is, it might be applied towards the various types of decision-making processes and in our proposed model has significantly increased the efficiency of decision-making process to find out the problem.

\section{REFERENCES}

Chiu, Y. J., Chen, H. C., Tzeng, G. H., Shyu, J. Z. (2006). Marketing strategy based on customer behaviour for the LCD-TV, International Journal and Decision Making ,7(2/3), 143-165.

Hatcher, M. (1994). Voting and priorities in health care decision making, portrayed through a group decision support system, using analytic hierarchy process, Journal of Medical System, 18 (5), 267-288.

Hori, S., Shimizu, Y. (1999). Designing methods of human interface for supervisory control systems, Control Engineering Practice 7(11), 1413-1419.

Hung, Y.H., Chou, S.C.T., Tzeng, G.H. (2006). Using a fuzzy group decision approach-knowledge management adoption. In APRU DLI 2006 conference, University of Tokyo, Japan,

Liberatore, M.J., Nydick R.L. (2008). The analytic hierarchy process in medical and health care decision making: A literature review, European Journal of Operational Research, 189, 194-207.

Lin, C. J., Wu, W.W. (2008). A causal analytical method for group decision-making under fuzzy environment, Expert Systems with Applications, 34(1), 205-213.

Liou, J. J. H., Tzeng, G. H., Chang, H. C. (2007). Airline safety measurement using a novel hybrid model, Journal of Air Transport Management,13(4), 243-249.

Saaty, T. L. (1980). The analytic hierarchy process. New York: McGraw-Hill.

Sloane, E.B., Liberatore, M.J., Nydick, R.L. (2002). Medical decision support using the Analytic Hierarchy Process., Journal of Healthcare Information Management ,16 (4), 38- 43.

Tzeng, G. H., Chiang, C. H., Li, C. W. (2007). Evaluating intertwined effects in e-learning programs:A novel hybrid MCDM model based on factor analysis and DEMATEL, Expert Systems with Applications 32(4), 1028-1044.

Yuksel, I., Kurt M. (1998). Determining the physicians work difficulties dimensions, National Productivity Centre of Turkey 6. Ergonomics Congress, 22-23 May, 631-642

Wu, W.W., Lee, Y. T. (2007). Developing global managers' competencies using the fuzzy DEMATEL method, Expert Systems with Applications, 32(2) 499-507. 